\title{
Conductor Development for High Energy Physics--Plans and Status of the U.S. Program
}

\author{
Ronald M. Scanlan
}

\begin{abstract}
In order to provide a cost effective high field magnet option for the next generation HEP accelerator, higher performance $\mathrm{Nb}_{3} \mathrm{Sn}$ superconductor is required. These requirements have been recognized by the DOE, and a conductor development program has been initiated. The goal is to produce a cost-effective conductor with a $\mathrm{Jc}$ (noncopper,12T,4.2K) exceeding $3000 \mathrm{~A} / \mathrm{mm}^{2}$ and an effective filament size of less than 40 micrometers. Although the Nb3Sn conductors manufactured at present have produced $\mathrm{Jc}$ values in excess of $2200 \mathrm{~A} / \mathrm{mm}^{2}$, no conductor being manufactured at present can achieve both the aggressive $\mathrm{Jc}$ and effective filament size goals. The first phase of the present program is underway, and is focused on improving the understanding of the factors that control Jc. Samples are being manufactured by industry and are being characterized with respect to $\mathrm{Jc}$ and magnetization as a function of composition and heat treatment condition. Using this new knowledge as a base, the program will move into a fabrication scale-up phase where the performance and cost-effectiveness can be demonstrated on production size quantities. The status and accomplishments of this program will be reviewed, and the plans for the scale-up program will be presented.
\end{abstract}

\section{Index Terms $-\mathrm{Nb}_{3} \mathrm{Sn}$, accelerator magnets}

\section{INTRODUCTION}

Historically, the improvements in performance of accelerator dipole magnets have been tied closely to improved superconductors. For example, the Tevatron used a $\mathrm{NbTi}$ conductor with a $\mathrm{Jc}(5 \mathrm{~T}, 4.2 \mathrm{~K})=1800 \mathrm{~A} / \mathrm{mm}^{2}$ to reach an operating field of $4.5 \mathrm{~T}$, whereas the SSC dipole magnets achieved a field of $6.6 \mathrm{~T}$ using an improved $\mathrm{NbTi}$ conductor with a $\mathrm{Jc}(5 \mathrm{~T}, 4.2 \mathrm{~K})=2750 \mathrm{~A} / \mathrm{mm}^{2}$. The $\mathrm{LHC}$, presently under construction, will operate at a field of $8.6 \mathrm{~T}$ using $\mathrm{NbTi}$ superconductor at a reduced temperature of $1.8 \mathrm{~K}$. However, the LHC is pushing near the practical limit for $\mathrm{NbTi}$, and to continue the advance to higher fields, a superconductor with higher upper critical field, $\mathrm{Bc}_{2}$, must be used. In contrast to $\mathrm{NbTi}$, all prospective higher field superconductors are brittle materials, so new conductor fabrication and magnet fabrication techniques must be developed.

At present, $\mathrm{Nb}_{3} \mathrm{Sn}$ is the only practical choice in terms of properties, availability, and price. The $\mathrm{Nb}_{3} \mathrm{Sn}$ conductor currently being used in the HEP magnet R\&D programs has a $\mathrm{Jc}(12 \mathrm{~T}, 4.2 \mathrm{~K})$ greater than $2000 \mathrm{~A} / \mathrm{mm}^{2}$, and the price is not prohibitive for the relatively small quantities needed for these

Manuscript received Sept. 19, 2000. This work was supported by the U.S. Dept. of Energy under Contract No. DE-AC03-76F00098.

R. M Scanlan is with Lawrence Berkeley National Laboratory, Berkeley, CA 94720 USA (tel. 510-486-7241, e-mail: rmscanlan@lbl.gov)
R\&D magnets. However, in order to achieve a cost-effective high field dipole for a future high field hadron collider, the Jc must be improved and at the same time, the conductor cost must be reduced. The Advanced Technology Development Program in DOE recognizes this, and is taking an active role in promoting cost-effective high field conductor development in industry. In this paper, we discuss the conductor development goals, the long-term program strategy, and the results of the program to date.

\section{CONDUCtor DEVElopment PROgRam GoAls}

The basic outline for this program was developed from discussions at HEP conductor workshops that were held in 1998 and 1999. These goals are derived from the needs presented by the magnet R\&D community, the potential performance improvements presented by the wire development groups, and the cost improvements projected by the wire manufacturers. The overall goal of the program is to provide a cost-effective, high-performance superconductor for the high-field magnets required for the next generation highenergy physics colliders. The target specifications for this conductor are listed in Table I. Improvement in the critical current density, in the non-copper component, is the highest priority, followed by reducing the effective filament diameter $\left(D_{\text {eff }}\right)$. Reducing the cost of the conductor through process improvements and large scale manufacturing techniques will be important in the later phases of this program.

TABLE I.

Target specifications for HEP conductor

$\begin{array}{ll}\text { Jc (noncopper, } 12 \mathrm{~T}, 4.2 \mathrm{~K}): & 3000 \mathrm{~A} / \mathrm{mm}^{2} \\ \text { Effective filament size: } & 40 \text { micrometers or less } \\ \text { Piece length: } & \text { Average piece lengths greater } \\ & \text { than } 10,000 \mathrm{~m} \text { in wire diameters of } \\ & 0.3-1.0 \mathrm{~mm} \\ \text { Wire cost: } & \text { Less than } \$ 1.50 / \mathrm{kA}-\mathrm{m}(12 \mathrm{~T}, 4.2 \mathrm{~K})\end{array}$

A conductor for a practical accelerator magnet will have other requirements in addition to those listed in Table I, such as sufficient copper to non-copper ratio to protect the magnet during quench. However, these parameters can be defined only in the larger context of magnet design, and thus are not specified at this time. The superconductor magnetization requirement, in particular, is under intensive study by the accelerator physics groups, and several innovative methods for accommodating a relatively large effective filament size are being proposed[1], [2]. This is important, since it appears 
that there is a tradeoff between $\mathrm{Jc}$ and $\mathrm{D}_{\mathrm{eff}}$ for many conductors under consideration in this program.

In addition to the technical considerations, another important factor shaping this program is the funding situation. The present program has been designed to take advantage of the very significant work being done in industry under the DOE SBIR program. Also, the University and National Laboratory groups who are members of the Conductor Development Group (see acknowledgement section) are doing much of the sample characterization and testing.

In section III, the experimental results and status of wire development will be reviewed. In the following section IV, the results of cabling studies on these wires will be presented. Finally, in section $\mathrm{V}$, the cost reduction plan will be described.

\section{EXPERIMENTAL RESULTS--WIRE DEVELOPMENT}

\section{A. $\mathrm{Nb}_{3} \mathrm{Sn}$}

At present, development work is proceeding on three types of conductor that show promise for meeting the requirements for the next generation collider--these are $\mathrm{Nb}_{3} \mathrm{Sn}, \mathrm{Nb}_{3} \mathrm{Al}$, and $\mathrm{Bi}-2212$. This paper will focus on $\mathrm{Nb}_{3} \mathrm{Sn}$; however, in order to present a complete picture, the status of $\mathrm{Nb}_{3} \mathrm{Al}$ and $\mathrm{Bi}$ 2212 conductor development will be summarized and references listed that provide a more complete discussion.

The bronze process for fabricating $\mathrm{Nb} 3 \mathrm{Sn}$ has been shown to be limited in overall Jc to levels below the interest for use in high field accelerator magnets, so the work described here is focussed on three $\mathrm{Nb}_{3} \mathrm{Sn}$ fabrication processes that have demonstrated Jc $(12 \mathrm{~T}, 4.2 \mathrm{~K})$ performance above 1500 $\mathrm{A} / \mathrm{mm}^{2}$. These are the modified jelly-roll (MJR), internal tin (IT), and the powder in tube (PIT).

Oxford Superconducting Technology (OST) is utilizing the MJR process, and they have supplied wire, or have orders for wire, from several accelerator magnet groups (BNL, FNAL, LBNL, and TAMU). Fig. 1 shows a cross section of the MJR wire supplied to LBNL for the common coil magnet.

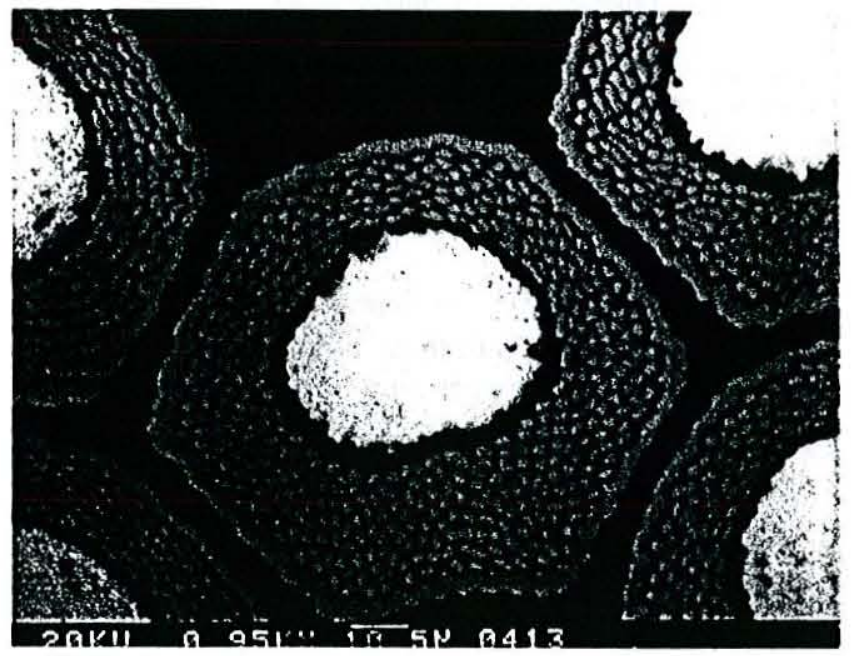

Fig. 1. MJR sub-element showing $\mathrm{Sn}$ core, $\mathrm{Nb}$ filaments, and $\mathrm{Nb}$ diffusion barrier. Sub-element width is 70 microns.
Two coils (designated RT-1) were fabricated from this conductor and tested in Feb., 2000. These coils reached a field of $12.2 \mathrm{~T}$, the short sample limit of the conductor, with minimal training [3]. Although a Jc(non-copper) exceeding $2200 \mathrm{~A} / \mathrm{mm}^{2}$ is being achieved, a shortcoming of this wire is residual resistivity ratio (RRR) of about 15 . Analysis of this wire showed that the $\mathrm{Nb}$ diffusion barrier was almost completely converted to $\mathrm{Nb}_{3} \mathrm{Sn}$ and that $\mathrm{Sn}$ had diffused into the copper matrix. OST has modified the conductor design to prevent this from occurring on new wire orders. This modification, and perhaps a modified heat treatment, is expected to restore the RRR to the levels in the conductor specification (RRR greater than 70). This problem notwithstanding, the coils performed very well in the RT-1 coil test. This result has prompted the magnet design team to reconsider the amount of high conductivity $\mathrm{Cu}$ matrix material that is required for good coil performance [4]. A set of inner coils, also using OST wire, have been completed and the magnet (RD-3) is under test.

Although the MJR process has been shown to produce a very high Jc conductor, there are some concerns with respect to process scaling and hence the potential for significant cost reductions. Also, it is not clear that the MJR process wire can reach the desired 40 micron effective filament diameter-- $D_{\text {eff }}$ is around 70 microns in the present wire. Consequently, OST is developing an alternative, called the hot extruded rod (HER) process [5], [6]. This is a variation of the hot extrusion process, which is used to produce NbTi billets weighing over $500 \mathrm{~kg}$ and has been shown to be very costeffective. In this instance, a Cu-matrix, Nb-rod composite billet is produced by hot extrusion (Fig 2). Since $\mathrm{Sn}$ has a low melting point and cannot be hot extruded, salt is substituted for the $\mathrm{Sn}$ and then washed out following extrusion. Then, Sn rods are inserted and the composite is drawn to final wire size. This process overcomes two major problems experienced by all high $\mathrm{Jc} \mathrm{Nb}_{3} \mathrm{Sn}$ processes: (1) poor bonding of the internal surfaces due to the absence of a hot extrusion step, and (2) scale-up limitations in a rod bundling and cold drawing process.

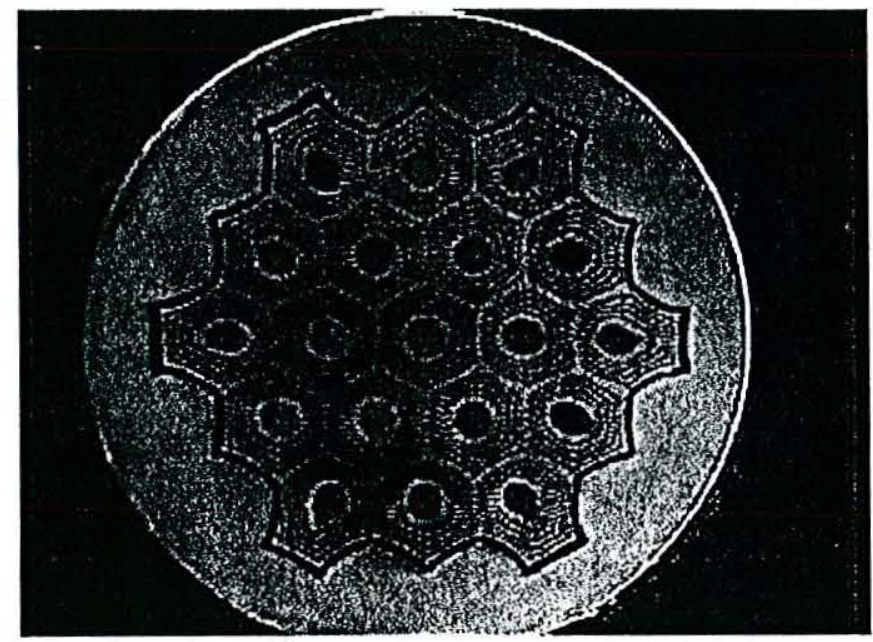

Fig. 2. Hot Extruded Rod Billet with salt packed into the hex-rod centers. 
Proof of principle experiments have been completed by OST, and design optimization work is in progress at OST as part of the new conductor development program [7]. In addition to the HER work, OST is performing some composition optimization work using $\mathrm{Nb}$ rods cabled with $\mathrm{Cu}$-clad $\mathrm{Sn}$ wires. This approach [8] allows a wide range of compositions to be studied, and the optimum Nb-Sn-Cu composition to be selected for HER billets.

The internal tin process is being pursued by IGC through conductor procurement orders, R\&D contracts, and a SBIR subcontract [9]. The goals of this program are to (1) optimize the composition to produce the highest Jc, consistent with a reliable manufacturing process, and (2) identify cost reduction tasks for a subsequent manufacturing scale-up phase. The ranges of $\mathrm{Nb}$ and $\mathrm{Sn}$ compositions under study are shown in Table II. Initial results [10] show that all the composites can be processed successfully as monocore wire; however, the highest $\mathrm{Nb}$ and $\mathrm{Sn}$ compositions exhibit some processing problems when fabricated as multicore wire. Jc tests of wires from this matrix are in progress. Preliminary results for a sample of wire from Billet EP2a shows a Jc $(12 \mathrm{~T}, 4.2 \mathrm{~K})=$ $1900 \mathrm{~A} / \mathrm{mm} 2$. A cross section of a $0.6 \mathrm{~mm}$ diameter wire from Billet EP2a is shown in Fig. 3. Analysis of the matrix composition after reaction shows a residual $\mathrm{Sn}$ content of 2.65 at\%, and some unreacted $\mathrm{Nb}$ in the cores of some filaments. EP2b, with more Sn available for reaction, should allow complete reaction of the $\mathrm{Nb}$. Note also that some $\mathrm{Nb}$ rods have been removed to subdivide the $\mathrm{Nb}_{3} \mathrm{Sn}$ in an attempt to reduce $D_{\text {eff. }}$.

TABLE II.

Internal Sn Composition Study Matrix

$\begin{array}{lllll}\begin{array}{l}\text { Billet } \\ \text { Number }\end{array} & \begin{array}{l}\text { Nb local } \\ \text { area ratio }\end{array} & \begin{array}{l}\mathrm{Nb} \\ \text { (at\%) }\end{array} & \begin{array}{l}\mathrm{Sn} \\ \text { (at\%) }\end{array} & \begin{array}{l}\mathrm{Cu} \\ \text { (at\%) }\end{array} \\ \text { EP1a } & 0.53 & 34.3 & 12.4 & 53.4 \\ \text { EP1b } & 0.53 & 29.1 & 16.2 & 54.7 \\ \text { EP2a } & 0.81 & 42.2 & 14.2 & 43.6 \\ \text { EP2b } & 0.81 & 45.0 & 16.0 & 39.0 \\ \text { EP3a } & 0.73 & 46.1 & 15.5 & 38.4 \\ \text { EP3b } & 0.73 & 51.3 & 17.3 & 31.4\end{array}$

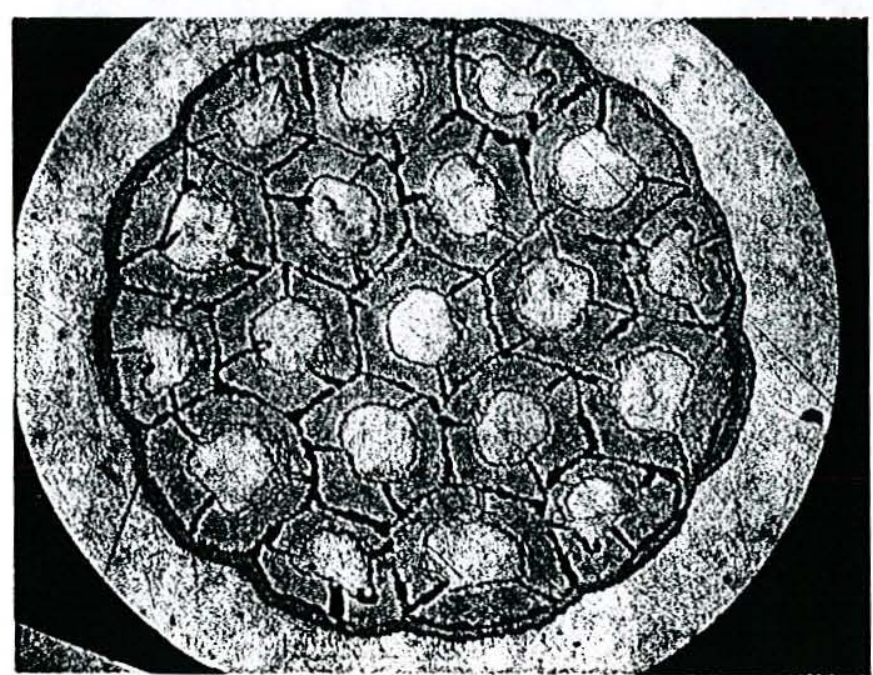

Fig. 3a. Cross-section of a 19 sub-element wire from billet EP2a, after reaction. Wire diameter is $0.6 \mathrm{~mm}$.

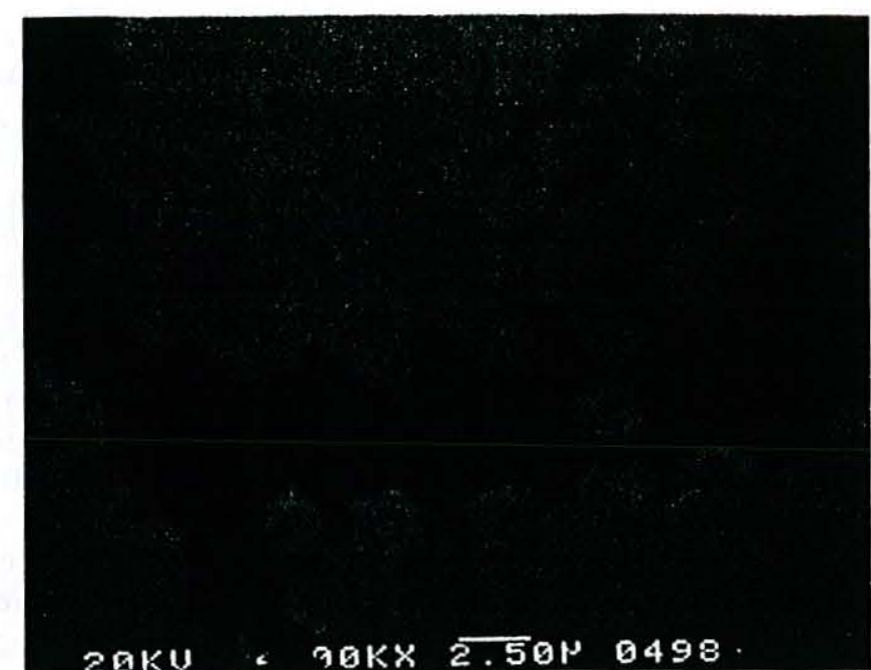

Fig. 3b. Higher magnification photo of the same wire, showing almost complete reaction as well as a significant amount of sintering of the $\mathrm{Nb}$ filaments within the sub-element arrays.

\section{B. $\mathrm{Nb}_{3} \mathrm{Al}$}

The transverse pressure applied to the conductor at the midplane of a shell type magnet, due to a combination of the applied prestress and the Lorentz forces, is very high. For example, the combined transverse stress reached about 150 $\mathrm{MPa}$ at 13.5 T in the LBNL D20 magnet. At this stress level, the $\mathrm{Jc}$ for $\mathrm{Nb}_{3} \mathrm{Sn}$ has decreased significantly, the order of $20 \%$, and the stress effect becomes more important at higher fields. The effect of stress on $\mathrm{Jc}$ is much lower in $\mathrm{Nb}_{3} \mathrm{Al}$, so $\mathrm{Nb}_{3} \mathrm{Al}$ is an attractive alternative to $\mathrm{Nb}_{3} \mathrm{Sn}$ for high stress, high field applications. Building upon earlier work performed in Japan and the U.S. in support of the fusion magnet programs, several HEP groups have been exploring the feasibility of using $\mathrm{Nb}_{3} \mathrm{Al}$ in accelerator magnets. $\mathrm{Nb}_{3} \mathrm{Al}$ produced by conventional processing does not provide a high Jc and Hc2, so recent R\&D is focused on a rapid quench process [11]. A facility for producing rapidly quenched wire in the U.S. has been developed by OSU [12], and precursor wire is being produced under several SBIR projects. Short sample results obtained in both the Japanese and U.S. programs look very promising, with Jc values (for the A15 phase area) over $1000 \mathrm{~A} / \mathrm{mm}^{2}$ at $15 \mathrm{~T}$. The main challenge is in the production of long lengths of precursor material for processing in the rapid quench apparatus.

Recently, however, new results and changes in magnet design approaches have changed the situation. Results obtained in the common coil program at LBNL [13] indicate that magnets can operate successfully at lower pre-stress levels. This information, together with the demonstration of stress management techniques [14] in dipole magnets, has resulted in a reassessment of the importance of a conductor that is more strain-tolerant than $\mathrm{Nb}_{3} \mathrm{Sn}$. Although a low strain sensitivity material in still a high priority for fusion magnets and perhaps NMR magnets as well, the priority is not so high as formerly believed for high field accelerator magnets. 


\section{HTS conductors}

Although the near term emphasis is on $\mathrm{Nb}_{3} \mathrm{Sn}$, the HTS conductors are of interest for extending the dipole magnet field range above 15-16 T. Bi-2212, in particular, can be fabricated into long lengths of round wire. These round wires have been cabled successfully to produce Rutherford type cables that can be used in react and wind racetrack coils [15]. Until recently, the critical current densities were still too low to be of interest for HEP magnets. However, new results [16] show that $\mathrm{Jc}$ values comparable to those for $\mathrm{Nb}_{3} \mathrm{Sn}$ can be achieved for fields above $15 \mathrm{~T}$. Also, measurements of the strain dependence of $\mathrm{Bi}-2212$ cables [17] indicate that this material has sufficient strain tolerance to be used in dipole magnets utilizing stress management approaches. Given the rapid pace of $\mathrm{Jc}$ improvements for $\mathrm{Bi}-2212$, it seems likely that the Jc will improve even more in the next few years. However, the main detriment to large-scale use remains the cost of this material relative to $\mathrm{NbTi}$ and $\mathrm{Nb}_{3} \mathrm{Sn}$. Costs are high due to the small scale of production, as is the case for $\mathrm{Nb}_{3} \mathrm{Sn}$, but in addition, $\mathrm{Bi}-2212$ conductor cost is high due the raw materials cost of the $\mathrm{Ag}$ matrix. Alternatives to $\mathrm{Ag}$, or methods of greatly reducing the amount of $\mathrm{Ag}$, are necessary developments to make Bi-2212 a cost-effective conductor.

YBCO coated conductors are receiving much attention for other applications, due to its higher operating temperature. This conductor may offer advantages for high field dipoles as well. However, for the near-term, this program will focus on conductors that have high Jc and have been fabricated in long lengths,

Figure 4 summarizes the current state of the art for the wires under consideration for high field dipole magnets. All three approaches being pursued for $\mathrm{Nb}_{3} \mathrm{Sn}$ are producing wires with $\mathrm{Jc}(12 \mathrm{~T}, 4.2 \mathrm{~K})$ above $2000 \mathrm{~A} / \mathrm{mm}^{2}$. Although the composition of the $\mathrm{Nb}_{3} \mathrm{Sn}$ is not uniform over the entire reaction layer, Jc values in the A15 layer are approaching $5500 \mathrm{~A} / \mathrm{mm}^{2}$. This result suggests (1) there is still more potential for higher intrinsic Jc values if the layer composition

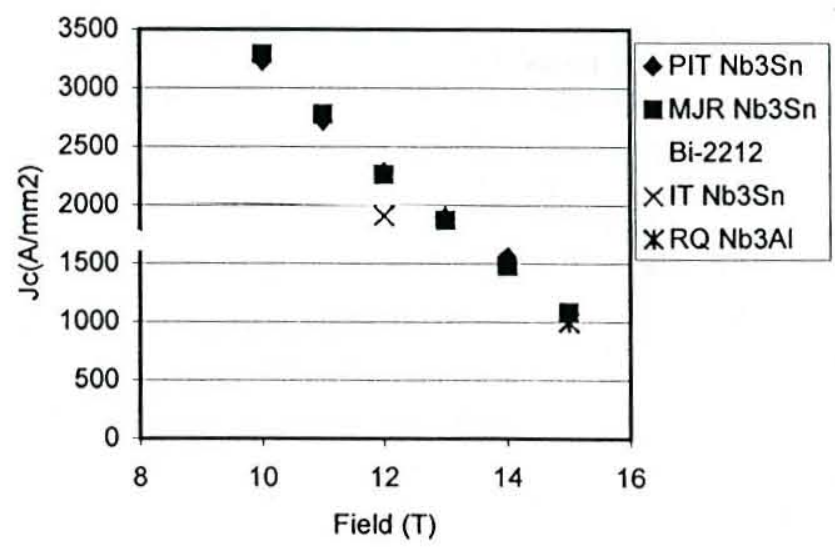

Fig. 4. Comparison of the best Jc values for $\mathrm{Nb}_{3} \mathrm{Sn}$ (PIT, MJR, IT), Nb3 $\mathrm{AI}$ (average of rapid quench data, based on Als area), and Bi-2212 (Showa) wires. can be optimized, and (2) even with the present value of $5500 \mathrm{~A} / \mathrm{mm}^{2}$ in the $\mathrm{Nb}_{3} \mathrm{Sn}$ layer, the Jc (non-copper) goal of $3000 \mathrm{~A} / \mathrm{mm}^{2}$ can be met if the $\mathrm{Nb}, \mathrm{Sn}$, and $\mathrm{Cu}$ volume fractions are optimized. The $\mathrm{Jc}$ data for $\mathrm{Nb}_{3} \mathrm{Al}$ indicate the extent that $\mathrm{Nb}_{3} \mathrm{Al}$ must be improved in order to be competitive with $\mathrm{Nb}_{3} \mathrm{Sn}$. Assuming a reasonable value for the residual $\mathrm{Nb}$ (matrix, plus diffusion barrier) of perhaps $50 \%$ of the non-copper area, the intrinsic $\mathrm{Jc}$ of the $\mathrm{Nb}_{3} \mathrm{Al}$ would need to be doubled in order to have a conductor comparable to the present $\mathrm{Nb}_{3} \mathrm{Sn}$. Finally, the new Jc data for $\mathrm{Bi}-2212$, extrapolated to higher fields, indicate a crossover with $\mathrm{Nb}_{3} \mathrm{Sn}$ at a field of around $14 \mathrm{~T}$. These data are all relatively recent, and further improvements are likely. Since it may be a decade before construction begins on the next hadron collider the relative positions of the three candidate conductors may change.

\section{EXPERIMENTAL RESULTS--CABLE DEVELOPMENT}

The $\mathrm{Nb}_{3} \mathrm{Sn}$ accelerator magnet programs rely on a flat, compacted (Rutherford) type cable developed initially for $\mathrm{NbTi}$ magnets. Cables of this type have been made successfully from $\mathrm{Nb}_{3} \mathrm{Sn}$; however, the cabling parameters must be modified to take into account the very different mechanical properties of the $\mathrm{Nb}-\mathrm{Cu}-\mathrm{Sn}$ composites compared with the NbTi-Cu composites. In particular, the high Jc wires described above, when made via a bundling and cold drawing process rather than a hot extrusion process, are susceptible to degradation during cabling due to shear, which can cause severe degradation of the electrical properties. Extensive shearing of the $\mathrm{Nb}$ tubes (PIT $\mathrm{Nb}_{3} \mathrm{Sn}$ wire) in a highly compacted cable results in $\mathrm{Sn}$ contamination of the $\mathrm{Cu}$ matrix and a serious drop in Jc. Cables compacted to a safe level and an over-compacted cable are shown in Fig. 5. Additional information on methods of reducing cabling degradation of PIT $\mathrm{Nb}_{3} \mathrm{Sn}$ is found in [18].

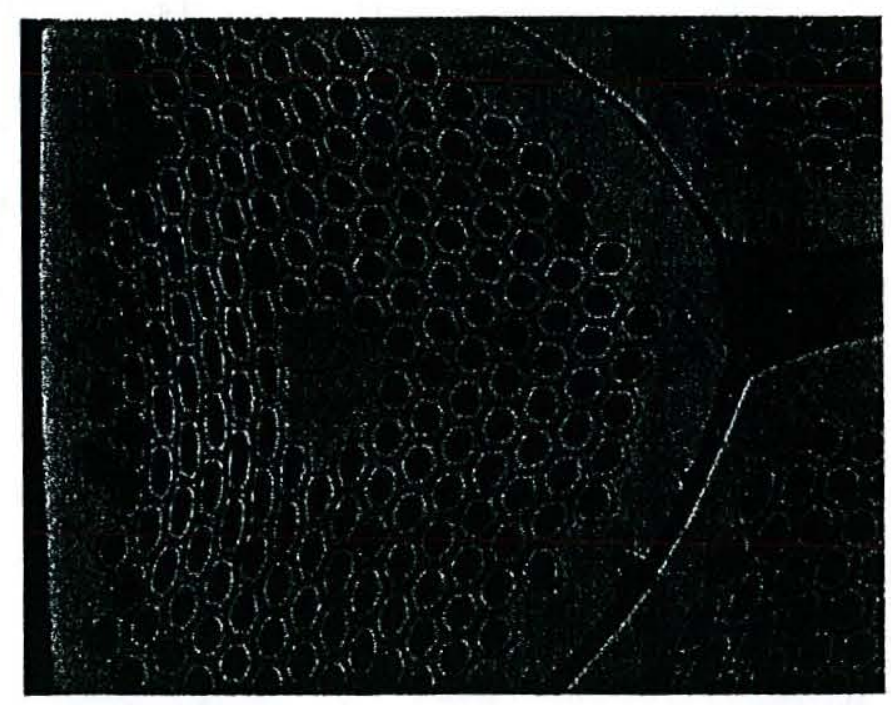

Fig.5a. PIT $\mathrm{Nb}_{3} \mathrm{Sn}$ strand at edge of moderately compacted cable, showing deformation without shearing.. 


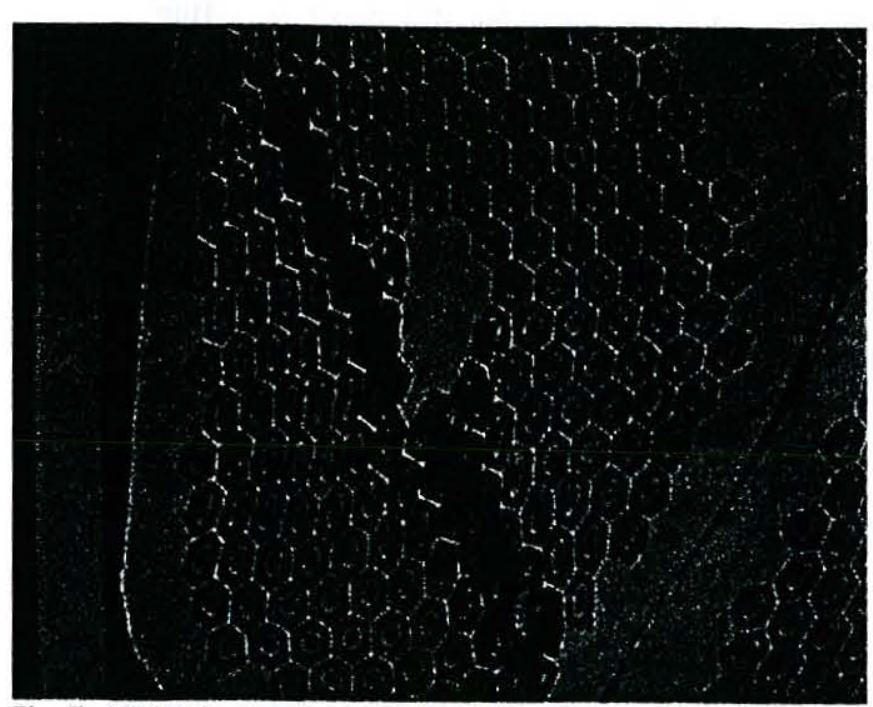

Fig. 5b. PIT Nb3 3 Sn strand at the edge of a heavily compacted cable, showing severe shearing of the $\mathrm{Nb}$ tubes in the composite wire.

Another type of degradation observed in $\mathrm{Nb}_{3} \mathrm{Sn}$ cables is Ic degradation as a result of pressure. All cables used in dipole magnets are exposed to some degree of pressure, either as a result of pre-stressing the coils, or as a result of the Lorentz forces when the magnet is energized. Ic degradation can be either reversible, due to the pressure dependence of the intrinsic superconducting properties, or, for high strains, irreversible due to fracture of the $\mathrm{Nb}_{3} \mathrm{Sn}$ filaments. In particular, the irreversible damage is of concern since it is progressive with cycling and also since it seems to depend on the type of conductor. For example, the Jc vs transverse strain characteristics appear to be different for cables made from IT wires and MJR wires [19]. Hence, Ic vs strain testing of cables for each type of strand is an important part of a conductor development program. Once the characteristic strain behavior of each type of conductor is known, finite element analyses of the composite strand and cable can be performed to predict magnet behavior [20].

In addition to degradation studies, the cabling work in support of this program is aimed at determining whether copper can be added at the cabling step as a cost-effective alternative to the present method of incorporating the copper necessary for quench protection into the individual strands. Pure $\mathrm{Cu}$ strands have been added successfully in a sub-cable, which was then cabled into a Rutherford cable (Fig. 6). Experiments are underway to add $\mathrm{Cu}$ strands at the Rutherford cable stage, but these attempts have not been successful to date; the mechanical properties of the $\mathrm{Cu}$ and superconductor need to be matched in order to prevent strands from popping out from the cable. A new series of experiments are in progress.

\section{COST REDUCTION PROgRam Plans}

As stated in Table I, the cost/performance goal for $\mathrm{Nb}_{3} \mathrm{Sn}$ wire is $\$ 1.50 / \mathrm{kA}-\mathrm{m}$ compared to the small volume, $\mathrm{R} \& \mathrm{D}$ conductor cost at present of about $\$ 7.00 / \mathrm{kA}-\mathrm{m}$. Obviously, it

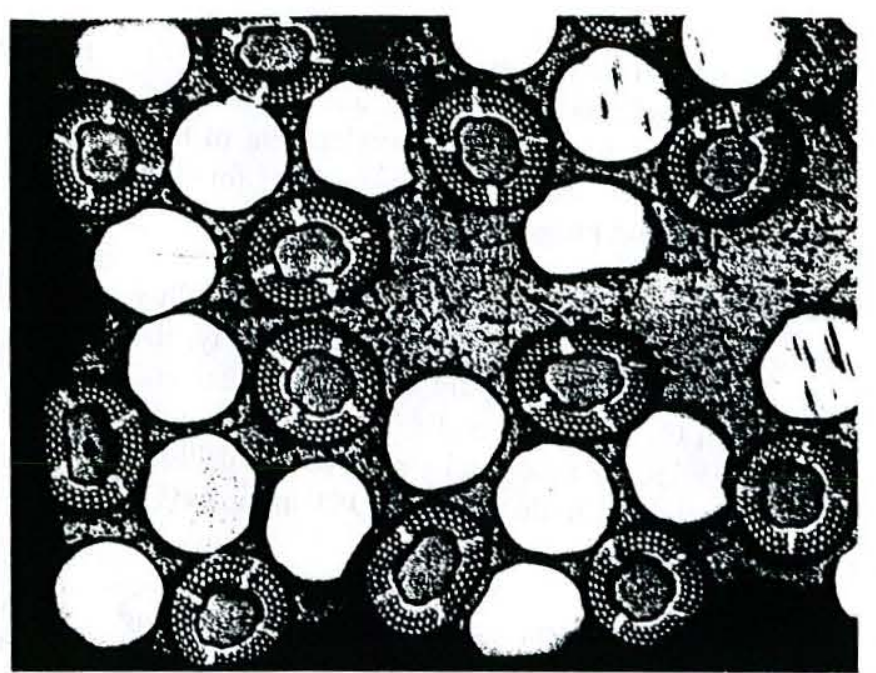

Fig. 6. Rutherford cable made from sub-cables with 4 copper and three superconductor strands. Strand diameter is $0.2 \mathrm{~mm}$.

will be easier to achieve this value if $\mathrm{Jc}$ can be increased from the present value of $2200 \mathrm{~A} / \mathrm{mm}^{2}$ to the target of 3000 $\mathrm{A} / \mathrm{mm}^{2}$. If this value is met, the cost goal for raw materials and processing steps is then $\$ 1.25 / \mathrm{m}$ or $\$ 285 / \mathrm{kg}$ for a $0.8 \mathrm{~mm}$ diameter wire. The contributions of processing costs and raw materials costs have been analyzed, and the key areas for improvement will now be discussed.

The program goal of $\$ 1.25 / \mathrm{m}$ is consistent with a detailed cost analysis performed and presented in another paper at this conference [9]. This analysis was performed for the internal tin process and is based on vendor quotations and extensive experience in the manufacturing of superconductor wire. Although this analysis was based on the internal tin process, it should be applicable to other $\mathrm{Nb}_{3} \mathrm{Sn}$ processes as well.

The wire model used is a basis for this analysis consists of a small diameter $(0.2-0.3 \mathrm{~mm})$ wire, with a single diffusion barrier and a single $\mathrm{Sn}$ core. In addition, a minimum amount of $\mathrm{Cu}$ is provided on the core, and additional $\mathrm{Cu}$, if required for protection, is introduced in a $1 \times 6$ subcable, in the manner shown in Fig 6.

In addition to the process innovations and process scale-up discussed above, it is important to understand and control the raw materials costs. These are discussed below:

1. Sn-Ti Alloy costs. One promising method for introducing $\mathrm{Ti}$ as an alloying element to raise $\mathrm{Hc} 2$ and $\mathrm{Jc}$ is in the form of Sn-Ti alloy. This alloy must be specially prepared in order to avoid large intermetallic particles of $\mathrm{Ti}_{6} \mathrm{Sn}_{5}$ that can cause wire breakage. At present, this alloy is fabricated in $22 \mathrm{~kg}$ ingots and costs $\$ 185 / \mathrm{kg}$. Fabrication of high quality Sn-Ti alloy on a large scale will be a high priority of the conductor manufacturing scale-up program.

2. $\mathrm{Nb}$ rod costs. The present cost of $\mathrm{Nb}$ rod at the stacking size of $12 \mathrm{~mm}$ diameter is $\$ 200 / \mathrm{kg}$. This cost can be reduced by a process analogous to that adopted for the $\mathrm{SSC}$ and LHC NbTi rods, in which the $\mathrm{Nb}$ (or NbTi) rods are obtained at large diameter, say $150 \mathrm{~mm}$, loaded into a $\mathrm{Cu}$ can and hot-extruded, followed by drawing to the 
billet stacking size. This process reduces the loss of $\mathrm{Nb}$ and the added cost of special lubricants and dies needed for the direct drawing of $\mathrm{Nb}$ rods. Development of this technology is another high priority project for the manufacturing scale-up program.

3. $\mathrm{Nb}$ tube costs. The present cost of $\mathrm{Nb}$ and $\mathrm{Nb}$ alloy tubes are even higher than $\mathrm{Nb}$ rod costs. Similarly, the costs can be reduced significantly by co-extrusion and co-drawing with $\mathrm{Cu}$ on the outer diameter and inside the tube. The $\mathrm{Cu}$ inside the tube can be removed by drilling, or a salt core analogous to that used by OST in their HER process can be used.

4. Diffusion barrier costs. Innovative methods of applying the diffusion barriers at near final size, such as the tube wrapping techniques being developed by Eurus, can reduce costs for the barrier [8]. Also, substitution of $\mathrm{NbTa}$ alloy for the Ta, which costs over $\$ 500 / \mathrm{kg}$ can result in significant cost savings.

This list of process improvements and raw materials cost savings is not meant to be all-inclusive. Instead, they are presented as examples of the areas that should be developed, and as incentives for others to contribute innovative ideas in this program.

\section{CONCLUSIONS}

1. High current density $\mathrm{Nb}_{3} \mathrm{Sn}$ shows promise for meeting the performance and cost goals for the next generation hadron collider.

2. In order to realize this potential, better understanding of properties controlling $\mathrm{Jc}$ in $\mathrm{Nb}_{3} \mathrm{Sn}$ is necessary. The first phase of the Conductor Development Program is focused on achieving these Jc improvements.

3. The cost/performance goal for $\mathrm{Nb}_{3} \mathrm{Sn}$ is ambitious, and will require significant scale-up effort to be realized. The subsequent phases of the Conductor Development Program will address these issues.

\section{ACKNOWLEDGMENTS}

The author acknowledges the key contribution of P.Limon in convincing the DOE sponsors and the FNAL management of the importance of this effort for the next hadron collider. Much of the credit for the successful launch of this program goes to the enthusiastic support of Conductor Development Group: G. Ambrosio (FNAL), E. W. Collings (Ohio State U.), D. Dietderich (LBNL), A. Ghosh (BNL), D.C. Larbalestier (U.W. Madison), P. Lee (U.W. Madison), P. Limon (FNAL), P. McIntyre (TAMU), B. Strauss (DOEHEP), and P. Wanderer (BNL).

We acknowledge the persistence and diligence of our industrial partners, Seung Hong and Jeff Parrell at OST; and Eric Gregory and Tae Pyong at IGC, in performing the R\&D work on the new conductor development program. Thanks to my colleagues at LBNL, Dan Dietderich and Kelly Molnar for the metallography accompanying this paper, and Hugh Higley for the cabling work.

\section{REFERENCES}

[1] V. V .Kashikhin and A. V. Zlobin, "Correction of the persistent current effect in $\mathrm{Nb}_{3} \mathrm{Sn}$ accelerator magnets," paper 3LA03, these proceedings.

[2] R. Gupta, "Common coil magnet system for VLHC," Proceedings of the 1999 Particle Accelerator Conf., IEEE Pub. No. 99CH36366, pp3239-3241, 1999.

[3] S. A. Gourlay et al, "Fabrication and testing of $\mathrm{Nb}_{3} \mathrm{Sn}$ racetrack coils at high field," paper $3 \mathrm{LE} 05$, these proceedings.

[4] A. D. McInturff, private communication.

[5] J. C. McKinnell et al, "Fully bonded Internal-Tin, Niobium-Tin $\left(\mathrm{Nb}_{3} \mathrm{Sn}\right)$ conductor development at Oxford Superconducting Technology," IEEE Trans on Applied Superconductivity ㄱ, pp1360-1363, 1997

[6] U. S. Patent No. 5534219

[7] M. Field et al, "Progress with $\mathrm{Nb}_{3} \mathrm{Sn}$ conductors at OST," paper 4MK08, these proceedings.

[8] S. Hong et al, "Internal Tin- $\mathrm{Nb}_{3} \mathrm{Sn}$ composite," IEEE Trans. On Magnetics 25, pp2215-2217, 1989.

[9] B. A. Zeitlin, E. Gregory, and T. Pyon, "A high current density low cost $\mathrm{Nb}_{3} \mathrm{Sn}$ conductor scaleable to modern $\mathrm{NbTi}$ production economics," paper 4MK06, these proceedings.

[10] T. Pyon and E. Gregory, "Nb${ }_{3} \mathrm{Sn}$ conductors for high energy physics and fusion applications," paper $4 \mathrm{MK} 07$, these proceedings.

[11] Y.Iijima et al, " $\mathrm{Nb}_{3} \mathrm{Al}$ multifilamentary wires continuously fabricated by rapid-quenching," Adv. In Cryo.Eng., 40, pp899-905, 1994.

[12] F. Buta et al, "Optimization studies for processing $\mathrm{Nb}_{3} \mathrm{Al}$ using a rapid ohmic heating and quenching method," paper $5 \mathrm{ML} 04$, these proceedings.

[13] S. A. Gourlay et al, "Fabrication and test results of a prototype, Nb3Sn superconducting racetrack dipole magnet," Proc. 1999 Particle Accelerator Conf., IEEE Pub. No. 99CH36366, pp171-173, 1999.

[14] A. Abreu et al, "Block-coil dipole for future hadron colliders,", IEEE Trans on Applied Superconcuctivity 9, pp705-708, 1999.

[15] R. M. Scanlan et al, "Fabrication and test results for Rutherford-type cables made from BSCCO strands," IEEE Trans. On Applied Superconductivity 9 , pp 130-133, 1999.

[16] Y. Aoki et al, "Improvement of superconducting properties of Bi-2212 round wire and primary test results of large capacity Rutherford cable," paper $2 \mathrm{MC} 03$, these proceedings.

[17] D. R. Dietderich et al, "Critical current variation in Rutherford cables of Bi-2212 in high magnetic fields with transverse strain," Conf. on Materials and Mechanisms of Superconductivity, May 2000, to be published in Physica C.

[18]. A. denOuden et al, "Progress in the development of an $88 \mathrm{~mm}$ bore 10 T Nb3Sn model dipole magnet," paper 4LB02, these proceedings.

[19] D. R. Dietderich et al, "Critical current of superconducting Rutherford cable in high magnetic fields with transverse pressure," IEEE Trans on Applied Superconductivity 9, pp 122-125.

[20] J. M. vanOort, "Critical current degradation in $\mathrm{Nb}_{3} \mathrm{Sn}$ superconductors in accelerator magnets," Ph.D Thesis, Univ. of Twente, The Netherlands, 2000. 